\title{
Select controversies in the management of methicillin-resistant Staphylococcus aureus bacteremia: answers and remaining questions from recent evidence
}

\author{
Jose F. Suarez ${ }^{1, x} \quad$ Sharon Ong'uti ${ }^{2, x} \quad$ Marisa Holubar ${ }^{2 *}$ \\ ${ }^{1}$ Jackson Memorial Hospital/University of Miami Miller School of Medicine, Division of Infectious Diseases, Miami, FL, USA \\ ${ }^{2}$ Stanford University School of Medicine, Division of Infectious Diseases and Geographic Medicine, Stanford, CA, USA \\ ${ }^{x}$ Contributed equally
}

\begin{abstract}
Methicillin-resistant Staphylococcus aureus (MRSA) bacteremia continues to cause significant morbidity and mortality despite advances in medical therapy. Vancomycin therapy remains the standard of care for most cases of MRSA bacteremia but has pharmacokinetic and pharmacodynamic limitations, dosing complications, and known toxicity. Welcomed clinical trials have recently addressed some of the controversies that plague this field, including optimization of vancomycin dosing and use of combination therapy. In this review, we discuss these trials and their implications for clinical care and future research.
\end{abstract}

\section{Keywords}

Methicillin resistance, Staphylococcus, Staphylococcus aureus, MRSA, bacteremia

\section{Peer Review}

The peer reviewers who approve this article are:

1. David B Cluck, Department of Pharmacy Practice, Bill Gatton College of Pharmacy, East Tennessee State University, Johnson City, TN, USA

Competing interests: No competing interests were disclosed.

2. Sara E Cosgrove, Department of Medicine, Division of Infectious Diseases, Johns Hopkins University School of Medicine, Baltimore, Maryland, USA

Competing interests: No competing interests were disclosed.

3. Margaret R Hammerschlag, Division of Pediatric Infectious Diseases, SUNY Downstate Medical Center, Brooklyn, NY, USA

Susannah Franco, Department of Pharmacy, SUNY Downstate Medical Center, Brooklyn, NY, USA

Competing interests: No competing interests were disclosed. 
*Corresponding author: Marisa Holubar (mholubar@stanford.edu)

Competing interests: The authors declare that they have no competing interests.

Grant information: The authors declare that no grants were involved in supporting this work.

Copyright: (C) 2021 Holubar M et al. This is an open access article distributed under the terms of the Creative Commons Attribution License, which permits unrestricted use, distribution, and reproduction in any medium, provided the original work is properly cited.

How to cite this article: Suarez JF, Ong'uti S and Holubar M. Select controversies in the management of methicillin-resistant Staphylococcus aureus bacteremia: answers and remaining questions from recent evidence. Faculty Reviews 2021 10:(66) https://doi.org/10.12703/r/10-66

Published: 31 Aug 2021, Faculty Reviews 10:(66) https://doi.org/10.12703/r/10-66 


\section{Introduction}

Staphylococcus aureus bacteremia (SAB) remains a distinct entity in the realm of infectious disease, singular in its ability to adhere to vascular structures, cause deep-seated infections, disseminate, and result in a high mortality despite targeted antibiotic therapy. In 2017, the Centers for Disease Control and Prevention estimated 120,000 cases of SAB in the US and 20,000 associated deaths. Of those cases, mortality was higher among those with methicillin-resistant Staphylococcus aureus (MRSA) bacteremia in comparison with their methicillinsusceptible counterparts ${ }^{1}$. MRSA bacteremia has been associated with longer hospitalizations, longer durations of bacteremia, more severe disease (as evidenced by higher Charlson comorbidity and Pitt bacteremia scores), and a higher 30-day mortality in comparison with methicillin-susceptible Staphylococcus aureus (MSSA) bacteremia².

MRSA bacteremia poses a particular challenge aside from its increased mortality. The first-line therapy, vancomycin, exhibits variable penetration into tissues, slow killing, known nephrotoxicity, and complex dosing requirements ${ }^{3}$. In addition, clinicians face a dearth of evidence upon which to make management decisions for patients with MRSA bacteremia. However, in recent years, clinical trials addressing some of these controversial topics have examined vancomycin dosing optimization and the use of combination therapy. In this article, we review select clinical trials (in adults) published in the last three years and discuss their implications for clinical care and future research.

\section{Optimizing vancomycin dosing}

The primary pharmacokinetic/pharmacodynamic (PK/PD) exposure target for all glycopeptide antibiotics, including vancomycin, is the ratio of the 24-hour area under the curve to the minimum inhibitory concentration (AUC/MIC). However, the AUC/MIC range that maximizes clinical efficacy while minimizing toxicity is unclear. In 2009, national guidelines recommended an AUC/MIC target of at least $400 \mathrm{mg}$ *hour/L and, despite limited data, promoted the use of trough (Cmin) monitoring as a surrogate given the challenges of calculating an accurate AUC/MIC in routine practice ${ }^{4,5}$. These recommendations were rapidly accepted.

However, a growing number of studies have called both the AUC/MIC target of at least $400 \mathrm{mg}$ *hour/L and the Cmin monitoring approach into question. Studies have reported increased nephrotoxicity with vancomycin AUC/MIC of at least $600 \mathrm{mg}$ *hour $/ \mathrm{L}^{6}$ despite being within the accepted target range of the 2009 national guidelines. This recommended target range was based on limited data from predominantly retrospective studies that suggested that a high AUC/MIC was associated with less clinical failure?

The PROVIDE trial was designed to address this issue and test the hypothesis that patients with MRSA bacteremia would experience less frequent treatment failure if they received higher vancomycin exposure, defined as exceeding a set PK/PD threshold $\left(\mathrm{AUC}_{\mathrm{MIC}} \mathrm{BMD}_{\mathrm{BMD}}>650 \mathrm{mg} *\right.$ hour$/ \mathrm{L}$ or $\mathrm{AUC} / \mathrm{MIC}_{\text {e-test }}>$ $320 \mathrm{mg}$ *hour/L depending upon whether the MIC was determined by broth microdilution [BMD] or e-test). This multicenter observational study prospectively evaluated the association between vancomycin exposure (using day 2 AUC/MIC) and treatment failure, defined as 30-day mortality or persistent bacteremia of at least 7 days, in patients with MRSA bacteremia ${ }^{8}$. Of the 265 evaluable patients, 18\% experienced treatment failure and $26 \%$ developed acute kidney injury (AKI). Treatment failure did not differ by high versus low vancomycin exposure $(21 \%$ vs. $11 \%, P=0.07)$, but high vancomycin exposure was associated with nephrotoxicity. Further analysis suggested an optimal AUC/MIC ceiling of $515 \mathrm{mg}$ *hour/L to maximize clinical efficacy while limiting nephrotoxicity. Owing to lack of power, the study was not able to define a lower bound of a target range.

The narrower target AUC/MIC range suggested by that study may be challenging to achieve in routine clinical practice. Based in part on the PROVIDE trial data, 2020 U.S. national guidelines added a ceiling to the goal AUC/MIC range, recommending a target AUC /MIC of 400 to $600 \mathrm{mg}$ *hour /L for MRSA bacteremia and other serious MRSA infections in adult patient ${ }^{9}$

These guidelines also recommended replacing Cmin-based dosing with AUC-guided dosing and monitoring'. Retrospective and simulation studies demonstrate that many patients can achieve the target AUC/MIC with Cmin levels of less than $15 \mathrm{mg} / \mathrm{L}$ when an MRSA isolate's vancomycin MIC is not more than $1 \mu \mathrm{g} / \mathrm{mL}$, indicating a lack of correlation between a vancomycin Cmin level and AUC/MIC target ${ }^{6,10}$. Furthermore, Cmin of greater than $15 \mathrm{mg} / \mathrm{L}$ has been associated with nephrotoxicity, which indicates that Cmin-based dosing can lead to unnecessary and excessive vancomycin exposure and patient harm. In contrast, studies found that using AUC-guided dosing is associated with decreased nephrotoxicity, reduced per-patient blood sampling, and lower doses overall without impacting clinical outcomes ${ }^{11,12}$. However, it is important to note that robust data regarding the clinical efficacy of AUC-guided dosing are not yet available.

The 2020 national guidelines outline two methods to achieve AUC-guided drug monitoring: first-order PK equations and Bayesian software programs. In addition to the discussion included in these guidelines, AUC-guided dosing implementation options and considerations have recently been reviewed and individual institutions have published real-world experience $^{12-15}$. Regardless of the method used, converting to an AUC-guided approach is often resource-intensive (financial, personnel time, and information technology enhancements) and may be most impactful if targeted at patients receiving more than 3 days of therapy to maximize value ${ }^{13}$. Areas of uncertainty include how to continue drug monitoring in patients who require vancomycin in the outpatient setting, where trough-based monitoring is most common and AUCguided dosing would be logistically challenging. Further prospective studies are needed to refine AUC/MIC targetand 
evaluate practical ways to achieve these goals in routine practice.

Despite optimizing dosing strategies, vancomycin may not be the drug of choice for some patients. MRSA bacteremia due to strains with vancomycin $\mathrm{MIC}_{\mathrm{BMD}}$ of greater than $1 \mu \mathrm{g} / \mathrm{mL}$ poses a particular challenge to vancomycin use, rendering the target AUC/MIC of 400 to 600 impossible to achieve with standard dosing. For these infections, the use of alternative agents is warranted ${ }^{9}$. Fortunately, despite local reports of the emergence of vancomycin resistance, MRSA isolates with vancomycin MIC of greater than $1 \mu \mathrm{g} / \mathrm{mL}$ remain uncommon in large epidemiologic studies ${ }^{16-18}$. Evidence also suggests that vancomycin MICs are often specific to the methodology used and that exact agreement between different methodologies is relatively uncommon ${ }^{19}$. For example, the e-test method consistently generates higher MICs than BMD, the reference standard $^{19}$. Clinicians must work with their local laboratory to confirm and interpret MRSA isolates with vancomycin MIC of greater than $1 \mu \mathrm{g} / \mathrm{mL}$.

\section{Combination therapy}

In vitro data demonstrate and in vivo data suggest that combining bactericidal antibiotics with activity against MRSA, such as vancomycin or daptomycin, with beta-lactams (antibiotics to which the organism is inherently resistant) enhances pathogen elimination ${ }^{20}$. Some mechanisms by which betalactams could enhance vancomycin's or daptomycin's activity include the following: reduction of the bacterial cell wall thickness, which could facilitate target access for vancomycin or daptomycin ${ }^{21}$; an increase in the negative charge of the cell membrane, which would facilitate binding of daptomycin (which acquires a positive charge when it complexes with calcium $)^{22,23}$; and the ability of beta-lactams to enhance production of antimicrobial peptides in the infected host, which could lead to enhanced bacterial killing ${ }^{22,24}$. Unfortunately, the theoretical advantage of combination therapy has not translated into consistent improvement of clinically significant outcomes in the real world. Indeed, recent prospective cohort studies and randomized controlled trials have yielded mixed results, and increased side effects and costs have been met with marginally meaningful clinical benefits in specific patient populations. A summary of some of these studies is provided in Table 1.

\section{Vancomycin combination therapy}

Vancomycin-based combination therapies have been used in clinical practice to treat serious MRSA infections for many years; however, supportive evidence from prospective clinical trials was lacking ${ }^{25}$. The CAMERA trial, a small proof-ofconcept study, found that vancomycin in combination with an anti-staphylococcal penicillin (flucloxacillin) shortened the duration of bacteremia by 1 day compared with vancomycin alone in patients with MRSA bacteremia ${ }^{26}$. This led to a larger, multicenter, open-label randomized controlled trial (CAMERA-2) that compared MRSA bacteremia patients who received vancomycin monotherapy (with a goal trough of $15-20 \mu \mathrm{g} / \mathrm{L}$ ) or daptomycin (dosed at $6-10 \mathrm{mg} / \mathrm{kg}$ per day) with those who received a combination of vancomycin plus an antistaphylococcal penicillin (flucloxacillin or cloxacillin) or cefazolin (used for those allergic to penicillin or receiving dialysis) ${ }^{27}$. Enrollment occurred 72 hours after a positive blood culture was obtained. The primary outcome was defined as a composite of 90-day mortality, persistent bacteremia at day 5, microbiological failure, and relapse.

Of the 174 patients who were randomly assigned to the combination group, 111 received flucloxacillin or cloxacillin $(64 \%)$ and 27 received cefazolin (16\%). Almost all of the 178 in the monotherapy arm received vancomycin alone (172, $97 \%$ ). The trial was stopped early by the data safety monitoring board at $80 \%$ recruitment because of a statistically significant increase in AKI in the combination group (23\% vs. $6 \%, 17.2 \%$ difference; $95 \%$ confidence interval [CI] 9.3-25.2\%) and no difference in the composite primary outcome. Of note, at the time of study closure, fewer patients who received monotherapy cleared their bacteremia at day 5 compared with those who received combination therapy (11\% vs. $20 \%$, difference $-8.9 \%, 95 \% \mathrm{CI}-16.6$ to $-1.2 \%$ ).

This robust study provides definitive evidence of nephrotoxicity with no clear evidence of clinical benefit when vancomycin combination therapy is used. However, broad generalizations are limited by the agents used in this study. First, only $3(2 \%)$ of 174 patients in the combination group received daptomycin and no vancomycin; this is important as vancomycin itself is known to be nephrotoxic and daptomycin combination therapy has shown some promise in other studies ${ }^{28,29}$. Second, most patients in the combination group received an anti-staphylococcal penicillin, which is also associated with nephrotoxicity. Notably, of the 27 patients who received vancomycin together with cefazolin, only one experienced AKI, suggesting that beta-lactams other than semisynthetic penicillins used in combination with vancomycin might be a safer alternative.

Two recent retrospective cohort studies support the idea that other beta-lactams when used in combination with vancomycin may lead to less nephrotoxicity ${ }^{30,31}$. In one such study of adults with MRSA bacteremia, Zasowski et al. compared 129 patients who received vancomycin alone with 229 patients who received vancomycin and cefepime (the latter had to be administered within 72 hours of starting vancomycin and for

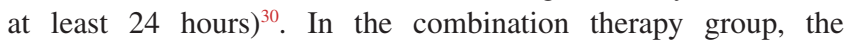
median duration of vancomycin received was 5 days (interquartile range [IQR] 4-9 days) and the median duration for cefepime was 3 days (IQR 2-4 days); those in the monotherapy group received a median of 6 days of vancomycin (IQR 4-10 days). There was no difference in nephrotoxicity between the two groups $(5.2 \% \text { vs. } 5.4 \%, P=0.940)^{30}$.

In another retrospective cohort study, Truong et al. compared 47 patients who received vancomycin monotherapy with 63 patients who received vancomycin and a beta-lactam. Of 


\section{Table 1. Table of summary statistics from studies comparing standard of care with combination therapy} in MRSA bacteremia management.

\begin{tabular}{|c|c|c|c|}
\hline Study & Monotherapy & Combination therapy & $P$ value \\
\hline \multicolumn{4}{|l|}{ CAMERA-2 trial $^{27}$} \\
\hline Study design & \multicolumn{2}{|c|}{ Open-label, randomized clinical trial } & \\
\hline Sample size & $n=178$ & $n=174$ & \\
\hline Intravenous line source & $12 \%$ & $14 \%$ & \\
\hline Treatment & VAN or DAP & VAN or DAP + beta-lactam ${ }^{a}$ & \\
\hline Composite primary outcome ${ }^{b}$ & $39 \%$ & $35 \%$ & 0.42 \\
\hline All-cause mortality (day 42) & $11 \%$ & $15 \%$ & 0.29 \\
\hline Persistent bacteremia (day 5) & $20 \%$ & $11 \%$ & 0.02 \\
\hline Toxicity outcome: AKI & $6 \%$ & $23 \%$ & $<0.001$ \\
\hline \multicolumn{4}{|l|}{ Zasowski et al. ${ }^{30}$} \\
\hline Study design & \multicolumn{2}{|c|}{ Retrospective cohort study } & \\
\hline Sample size & $n=129$ & $n=229$ & \\
\hline Treatment & VAN & VAN + cefepime & \\
\hline Endovascular source & $15.5 \%$ & $27.9 \%$ & 0.008 \\
\hline Primary outcome: microbiologic failure ${ }^{c}$ & $25.3 \%$ & $38.0 \%$ & 0.012 \\
\hline 30-day mortality & $7.8 \%$ & $20.5 \%$ & 0.002 \\
\hline $\mathrm{BSI} \geq 7$ days & $31.0 \%$ & $18.8 \%$ & 0.008 \\
\hline Vancomycin-associated nephrotoxicity ${ }^{d}$ & $5.4 \%$ & $5.2 \%$ & 0.94 \\
\hline \multicolumn{4}{|l|}{ Geriak et al. ${ }^{29}$} \\
\hline Study design & \multicolumn{2}{|c|}{ Pilot, prospective randomized study } & \\
\hline Sample size & $\mathrm{n}=21$ & $\mathrm{n}=17$ & \\
\hline Endovascular source & $35 \%$ & $47 \%$ & \\
\hline Treatment & VAN or DAP & DAP + ceftaroline & \\
\hline Treatment failure after 5 days, no. of patients ${ }^{g}$ & 3 & 1 & \\
\hline In-hospital mortality & $26 \%$ & $0 \%$ & 0.029 \\
\hline Bacteremia duration, median days & 3 & 3 & 0.56 \\
\hline AKI, no. of patients & 1 & 0 & \\
\hline \multicolumn{4}{|l|}{ Jorgensen et al. ${ }^{32}$} \\
\hline Study design & \multicolumn{2}{|c|}{ Retrospective, comparative cohort study } & \\
\hline Sample size & $n=157$ & $n=72$ & \\
\hline Endovascular source & $40.8 \%$ & $31.9 \%$ & \\
\hline Treatment & DAP & DAP + beta-lactame & \\
\hline Composite clinical failure & $27.4 \%$ & $12.5 \%$ & 0.013 \\
\hline 30-day mortality & $11.5 \%$ & $6.9 \%$ & 0.351 \\
\hline Persistent bacteremia at 5 days & $31.7 \%$ & $19.4 \%$ & 0.078 \\
\hline AKI & $2.9 \%$ & $10.8 \%$ & 0.046 \\
\hline Clostridioides difficile diarrhea & $1.3 \%$ & 5.6 & 0.08 \\
\hline \multicolumn{4}{|l|}{ McCreary et al..$^{33}$} \\
\hline Study design & \multicolumn{2}{|c|}{ Retrospective, multicenter, matched cohort study } & \\
\hline Sample size & $n=113$ & $n=58$ & \\
\hline Endovascular source & $53 \%$ & $53 \%$ & \\
\hline
\end{tabular}




\begin{tabular}{|c|c|c|c|}
\hline Study & Monotherapy & Combination therapy & $P$ value \\
\hline \multicolumn{4}{|l|}{ McCreary et al. ${ }^{33}$} \\
\hline Treatment & VAN or DAP & DAP + ceftaroline & \\
\hline Mortality within 30 days & $14.2 \%$ & $8.3 \%$ & $>0.05$ \\
\hline Median MRSA bacteremia duration (days) & 4.8 & 9.3 & $<0.001$ \\
\hline Bacteremia relapse/recurrence & $9.7 \%$ & $8.6 \%$ & NS \\
\hline \multicolumn{4}{|l|}{ Truong et al. ${ }^{31}$} \\
\hline Study design & \multicolumn{2}{|c|}{ Retrospective cohort study } & \\
\hline Sample size & $\mathrm{n}=47$ & $n=63$ & \\
\hline Treatment & VAN & VAN + beta-lactam ${ }^{h}$ & \\
\hline Endocarditis & $17.0 \%$ & $22.2 \%$ & 0.631 \\
\hline $\begin{array}{l}\text { Implantable cardioverter-defibrillator/cardiac } \\
\text { device }\end{array}$ & $2.1 \%$ & $4.8 \%$ & 0.634 \\
\hline Treatment failure & $41.9 \%$ & $30.4 \%$ & 0.291 \\
\hline MRSA-related inpatient mortality & $11.1 \%$ & $8.2 \%$ & 0.740 \\
\hline Persistent bacteremia & $18.6 \%$ & $19.3 \%$ & 1.000 \\
\hline$A K I^{k}$ & $19.2 \%$ & $14.3 \%$ & 0.604 \\
\hline
\end{tabular}

AKI, acute kidney injury; BSI, blood stream infection; DAP, daptomycin; MRSA, methicillin-resistant Staphylococcus aureus; NS, not significant; VAN, vancomycin.

aeta-lactam included flucloxacillin, cloxacillin, or cefazolin.

${ }^{b}$ Composite primary outcome, four components: all-cause mortality, persistent bacteremia at study day 5, microbiological relapse defined as a positive blood culture for MRSA at least 72 hours after a preceding negative culture, and microbiological treatment failure defined as a positive sterile site culture for MRSA at least 14 days after randomization

'Microbiologic failure, defined as a BSI duration of at least 7 days and/or MRSA BSI recurrence within 60 days of the end of MRSA BSI therapy

dVancomycin-associated nephrotoxicity defined as a serum creatinine increase of $0.5 \mathrm{mg} / \mathrm{L}$ and $50 \%$ from baseline on two consecutive measurements from initial vancomycin dose to 72 hours after the last dose

eBeta-lactam included cefepime, cefazolin, ceftaroline, ceftriaxone, meropenem, piperacillin-tazobactam, ertapenem, and ampicillin-sulbactam.

60-day mortality or 60-day recurrence or both

gPersistent MRSA bacteremia after 5 days

hBeta-lactam included piperacillin-tazobactam, ceftriaxone, ceftaroline, cefepime, and meropenem.

'Composite of clinical and microbiologic failure

Defined as 5 days of positive MRSA blood cultures

${ }^{k}$ An increase in serum creatinine by $50 \%$ or $0.5 \mathrm{mg} / \mathrm{dL}$, whichever was greater, from baseline in accordance with RIFLE (risk, injury, failure, loss, end-stage renal disease) criteria.

those in the combination group, $34(54 \%)$ received piperacillin-tazobactam, $4(6.4 \%)$ ceftriaxone, $2(3.2 \%)$ ceftaroline, and $2(3.2 \%)$ cefepime while 20 patients $(31.8 \%)$ received multiple beta-lactams during their treatment course ${ }^{31}$. Combination therapy was started a median of 5 hours (IQR 2-16 hours) from the onset of MRSA bacteremia, and the median duration of beta-lactam therapy was 6 days (IQR 3-9). The authors observed virtually no difference in adverse events (including nephrotoxicity) between the two groups, reporting 11 in the monotherapy group and 12 in the combination group $(23.4 \% \text { vs. } 19.1 \%, P=0.816)^{31}$. Of note, this is in contrast to increasing evidence from other retrospective trials that suggest that the combination of vancomycin and piperacillin/ tazobactam is associated with nephrotoxicity ${ }^{34,35}$. The heterogenous study populations and regimens used in these studies make firm conclusions challenging.

A large randomized controlled trial of vancomycin in combination with a first- or second-generation cephalosporin such as cefazolin could help determine if this regimen is a useful and less toxic alternative for particular patient populations with hard-to-treat MRSA bacteremia. However, this type of study is likely not feasible. Given the current level of evidence, combination vancomycin and beta-lactam regimens should not be the standard of care for MRSA bacteremia and, when used as a salvage regimen, should be combined with efforts to reduce nephrotoxicity, such as optimizing vancomycin dosing and avoiding anti-staphylococcal penicillins. 


\section{Daptomycin combination therapy}

Daptomycin dosed at $6 \mathrm{mg} / \mathrm{kg}$ per day has been associated with the emergence of resistant MRSA strains and associated treatment failure ${ }^{36}$. Despite the use of higher doses $(8-10 \mathrm{mg} / \mathrm{kg}$ per day), treatment failure has also been reported $^{37}$. Combination therapy has been explored as a mechanism to prevent the emergence of daptomycin resistance. Daptomycin in combination with beta-lactams is an attractive alternative to vancomycin combination therapy given its favorable toxicity profiles. Retrospective studies suggest that this combination may be a reasonable alternative for salvage therapy in the setting of treatment failure. However, prospective studies addressing this combination have been limited in number.

Geriak et al. compared the combination of daptomycin with ceftaroline, a fifth-generation cephalosporin with activity against MRSA, versus vancomycin or daptomycin monotherapy in a small pilot prospective study $^{29}$. Forty patients with MRSA bacteremia from three hospitals were randomly assigned at 72 hours of the initial blood culture to receive either combination therapy of daptomycin $6-8 \mathrm{mg} / \mathrm{kg}$ daily and ceftaroline $600 \mathrm{mg}$ every 8 hours $(\mathrm{n}=17)$ or monotherapy (vancomycin, $\mathrm{n}=21$; daptomycin, $\mathrm{n}=2$ ). The primary outcome was a composite of in-hospital mortality and bacteremia duration. The study was stopped early by the investigators because of a mortality difference observed at 90 days: 7 (30\%) deaths in the monotherapy group and none in the combination therapy group $^{29}$.

The limitations of this study have been discussed ${ }^{29,38}$. First, the small sample size suggests that the results should be considered only hypothesis-generating and not practicechanging, as was emphasized by the authors. Second, there were important differences between baseline patient characteristics in both groups, most notable of which was that five patients in the monotherapy group had an active malignancy, two of which had end-stage lung cancer, conditions which might have contributed directly to mortality. In contrast, the mean duration of bacteremia did not differ between the two arms, suggesting that factors other than microbiological efficacy contributed to the difference in mortality. Third, as with the CAMERA-2 trial, daptomycin monotherapy was under-represented; only two patients received this regimen. In addition, in the real world, the cost of therapy must be considered. The average daily cost when daptomycin (6-10 mg/kg IV every 24 hours) is combined with ceftaroline ( $600 \mathrm{mg}$ IV every 12 hours) is about 10 times the cost of standard of care ${ }^{39}$. Some advocate for higher dosing of ceftaroline when used for endovascular infections (600 mg IV every 8 hours), which would further increase costs. Of note, clinical success has been described with both dosing strategies ${ }^{40-42}$.

Some observations from this study are noteworthy. First, dual therapy was limited to a small fraction of the antibiotic course (mean of 8 days), suggesting the possibility that combination therapy is not necessary for the entire course of treatment, which could limit costs. This has also been observed in other small retrospective clinical trials ${ }^{43}$, and de-escalation to a single agent has shown promise in in vitro analyses ${ }^{21}$. Second, close to $50 \%$ of participants in both groups had a primary endovascular infection as defined by infective endocarditis, cardiac device-associated infections, and vascular/vascular graft infections. This is in contrast to the CAMERA-2 trial, in which this group represented only 10 to $30 \%$ of the enrollees. One might hypothesize that patients with primary endovascular infection represent a unique patient population and will particularly benefit from combination therapy ${ }^{28}$; future research focused in this direction would be useful.

The use of daptomycin and ceftaroline combination therapy showed promise in a retrospective matched cohort study. McCreary et al. matched MRSA bacteremia patients who received daptomycin plus ceftaroline for at least 72 hours at any point in therapy $(n=58)$ with those who received vancomycin or daptomycin monotherapy or both $(\mathrm{n}=113)^{33}$. Of those in the monotherapy arm, 96\% received vancomycin initially, but $63(56 \%)$ of 113 these patients were switched to an alternative monotherapy regimen, most commonly daptomycin (46/63, $73 \%$ ), at some point in their course (data not reported) ${ }^{33}$. Combination therapy was used as both initial therapy (within 72 hours of index positive culture) and salvage therapy (51\% second, $46 \%$ third, and $3 \%$ fourth regimen used), leading to the inclusion of a heterogenous population of patients. Switching to combination therapy early was associated with a shorter median duration of bacteremia (5 versus 11.5 days for those switched within 72 hours vs. after 72 hours, respectively; $P<0.001$ ), but overall mortality was similar between the two groups $(8.3 \%$ in combination group vs. $14.2 \%$ in monotherapy group, $P>0.05)$. The interpretation of these results is limited by the heterogeneous patient population and treatment regimens introduced by non-randomized treatment options.

A retrospective study addressing the prohibitive cost associated with the combination of daptomycin and ceftaroline was recently published ${ }^{32}$. Jorgensen et al. developed a propensitymatched retrospective cohort study in two hospitals in Detroit and compared MRSA bacteremia patients who received daptomycin monotherapy with those who received daptomycin in combination with a beta-lactam other than ceftaroline (cefepime $\mathrm{n}=31,43 \%$ or cefazolin $\mathrm{n}=18,25 \%)^{32}$. Patients were included if they received at least 5 days of daptomycin started within 120 hours of the index blood culture and at least 24 hours of a beta-lactam started within a day of daptomycin initiation. The initial choice of therapy was at the discretion of the primary team. The primary outcome was a composite of clinical failure (60-day all-cause mortality) or microbiological failure (recurrent positive blood culture after initial negative $)^{32}$. Patients in the combination therapy group experienced less clinical failure (9 patients [12.5\%] vs. 43 patients [27.4\%], $P=0.013)$, but only recurrent bacteremia achieved statistical significance. Similar to another study of patients with MSSA bacteremia ${ }^{44}$, AKI was more common in the combination group although chronic renal insufficiency was more frequent in the monotherapy group (10\% vs. $2.9 \%$ ). 
Retrospective studies can be challenging to interpret and, in the absence of randomized clinical trials, have an outsized and problematic influence on the standard of clinical care. The lack of randomization in these studies allows for confounders that cannot be fully addressed in the statistical analysis. For example, selection bias and confounding by indication are common problems as the regimens used are heavily influenced by a patient's clinical presentation and existing institutional policies/guidelines. In addition, the management between and within comparison groups may vary significantly and is incompletely documented (treatment duration, source control, antibiotic dosing, and so on). Ideally, findings from retrospective studies should be tested in a prospective randomized clinical trial before informing standard of care $^{45}$.

Multiple retrospective studies were included in a recent meta-analysis of 1636 patients from nine studies (four are reviewed in this article ${ }^{30-33}$ ) that compared MRSA bacteremia or endocarditis patients who received vancomycin or daptomycin monotherapy with those who received either drug in combination with a beta-lactam ${ }^{46}$. Clinical failure rates were significantly lower in those who received combination therapy compared with monotherapy (odds ratio [OR] 0.56 , CI $0.39-0.79 ; P<0.01)$ with lower rates of bacteremia relapse (OR 0.63, CI $0.43-0.92 ; P=0.02$ ) and persistent bacteremia (OR 0.56, CI $0.43-0.75 ; P=0.01$ ). But again, there was no difference in mortality and nephrotoxicity between the two groups, and the definition of clinical failure rates differed between studies. Some of these outcomes were influenced by the duration of bacteremia. Well-designed clinical trials are necessary to evaluate the efficacy of daptomycin in combination with lower-cost and narrower-spectrum beta-lactams.

\section{Other combination therapy}

There is growing interest in the clinical efficacy of daptomycin in combination with antibacterials other than beta-lactams but limited prospective evidence to inform this practice. One exception is the combination of fosfomycin and daptomycin.

In vitro studies demonstrate synergistic activity between daptomycin and fosfomycin, a broad-spectrum bactericidal antibiotic with activity against MRSA $^{47-49}$. A recent open-label, multicenter, randomized clinical trial in patients with MRSA bacteremia and endocarditis compared daptomycin monotherapy $(10 \mathrm{mg} / \mathrm{kg}$ per day) with the combination of daptomycin and intravenous fosfomycin $(2 \mathrm{~g} \text { every } 6 \text { hours })^{50}$. The protocol directed that the duration of treatment be 10 to 14 days for uncomplicated bacteremia and 28 to 42 days for complicated bacteremia. The primary endpoint was treatment success 6 weeks after the end of therapy.

A total of 82 patients received combination therapy while 85 patients received daptomycin monotherapy. In the modified intention-to-treat population, 74 patients received combination treatment and 81 received standard therapy. Treatment success was attained in $54.1 \%$ in the combination arm and $42 \%$ in the monotherapy arm (relative risk 1.29, CI $0.93-1.8$; $P=0.133$ ). No cases of clinical or microbiological failure were observed in the combination group compared with $14.8 \%$ in the monotherapy arm $(P<0.001)$. At 6 weeks, combination therapy was associated with lower rates of complicated bacteremia $(16.2 \%$ vs. $32.1 \% ; P=0.022)$. There was no significant difference in overall mortality between the two groups. The incidence of adverse events leading to treatment discontinuation was higher in the combination group (17.6\% vs. $4.9 \%$; $P=0.012)$.

Although there were no significant differences between the two groups, the study population may have represented a less sick population compared with other studies. The median number of days of therapy administered to both groups was 14 days, suggesting that most of the patients in this study had uncomplicated disease, which limits generalizability of this study, especially to those with difficult-to-treat infections for which non-standard therapy is often considered. Another criticism is that this study was not blinded, introducing potential bias. Though available in other countries, the intravenous formulation of fosfomycin is not currently approved for use in the US but it is being reviewed for use in complicated urinary tract infections ${ }^{51}$.

More studies examining non-beta-lactam antibiotics as the second agent are warranted. One such study that is currently enrolling is the CASSETTE trial, an open-label randomized controlled trial that will compare patients with severe $S$. aureus infection who receive standard treatment with those who also receive clindamycin administered for 7 days ${ }^{52}$.

\section{Persistent bacteremia: does the duration of bacteremia matter?}

$S$. aureus is the most common cause of persistent bacteremia (occurring in up to $39 \%{ }^{53}$ of cases) and is associated with metastatic infections and relapse $\mathrm{s}^{54,55}$. The very definition of "persistence" is controversial and multiple variations are used in the literature, ranging from at least 2 days to more than 7 days ${ }^{56}{ }^{57}$. The 2011 U.S. national guidelines, which are being revised, recommended re-evaluating treatment when bacteremia per-sists for at least 7 days despite appropriate antibiotic therapy. What further complicates this issue is that the duration of bac-teremia is a function of adequate source control, which can be challenging to achieve in clinical practice and is inconsistently documented in clinical trials ${ }^{58}$.

But does duration of bacteremia matter when it comes to relevant clinical outcomes? Combination therapy led to shorter durations of bacteremia in the studies reviewed above, yet there was no difference in mortality in most of these studies. Despite this, two recently published prospective observational studies suggest that duration of bacteremia does $\operatorname{matter}^{59,60}$. In a secondary analysis of a multicenter prospective observational cohort study of patients with SAB, 90-day mortality increased if bacteremia persisted for more than 2 days (adjusted hazard ratio 1.93 , CI 1.51-2.46; $P<0.0001)^{59}$. Of note, only 105 $(11 \%)$ of the 987 patients in this analysis had an MRSA infection. In a prospective observational study of 884 patients with SAB (290, 33\% MRSA), Minejima et al. found that 30-day 
mortality increased with a longer duration of bacteremia ${ }^{60}$. Each additional day of bacteremia was associated with a relative risk of death of 1.16 (CI 1.10-1.22; $P<0.0001$ ), and a significant increase in mortality risk was seen at 3 days.

Persistent bacteremia often leads to reconsideration of the administered therapy, but failure to detect and remove the focus of infection is the most important driver in most cases. Persistently positive blood cultures should prompt clinicians to search diligently for a persistent source of infection early in the course of therapy. When there is no evidence to suggest an undrained foci of infection, use of an alternative agent may be justified, especially in critically ill patients.

\section{Conclusions}

The optimal treatment of MRSA bacteremia remains unclear. Multiple barriers, including inconsistent case definitions and achieving adequate sample size, prevent the completion of high-quality randomized controlled trials designed to clearly answer challenging clinical questions ${ }^{45}$. Despite the large number of retrospective studies published, the ideal empiric and definitive antibacterial regimens that optimize clinical efficacy and minimize harm remain unknown.

The most critical clinical trials needed in SAB management are those addressing in which patients combination therapy is warranted, whether AUC-guided vancomycin dosing improves patient outcomes, and in which clinical situation agents such as ceftaroline monotherapy, long-acting agents, or oral therapy is appropriate. Finally, future studies should incorporate new statistical methods such as the desirability of outcome ranking (DOOR) approach, which combines both efficacy and toxicity outcomes into one global outcome in order to produce results that are clinically meaningful ${ }^{61}$.
1. Kourtis AP, Hatfield K, Baggs J, et al:: Vital Signs: Epidemiology and Recent Trends in Methicillin-Resistant and in Methicillin-Susceptible Staphylococcus aureus Bloodstream Infections - United States. MMWR Morb Mortal Wkly Rep. 2019; 68(9): 214-9.

PubMed Abstract | Publisher Full Text | Free Full Text |

Faculty Opinions Recommendation

2. Austin ED, Sullivan SS, Macesic N, et al: Reduced Mortality of Staphylococcus aureus Bacteremia in a Retrospective Cohort Study of 2139 Patients: 2007-2015. Clin Infect Dis. 2020; 70(8): 1666-74. PubMed Abstract | Publisher Full Text | Free Full Text | Faculty Opinions Recommendation

3. Rybak MJ: The pharmacokinetic and pharmacodynamic properties of vancomycin. Clin Infect Dis. 2006; 42 Suppl 1: S35-9.

PubMed Abstract | Publisher Full Text | Faculty Opinions Recommendation

4. Rybak MJ, Lomaestro BM, Rotschafer JC, et al:: Vancomycin therapeutic guidelines: A summary of consensus recommendations from the infectious diseases Society of America, the American Society of Health-System Pharmacists, and the Society of Infectious Diseases Pharmacists. Clin Infect Dis. 2009; 49(3): 325-7.

PubMed Abstract | Publisher Full Tex

5. Kullar R, Davis SL, Levine DP, et al.: Impact of vancomycin exposure on outcomes in patients with methicillin-resistant Staphylococcus aureus bacteremia: Support for consensus guidelines suggested targets. Clin Infect Dis. 2011; 52(8): 975-81.

PubMed Abstract | Publisher Full Text

6. Pai MP, Neely M, Rodvold KA, et al.: Innovative approaches to optimizing the delivery of vancomycin in individual patients. Adv Drug Deliv Rev. 2014; 77 : 50-7.

PubMed Abstract | Publisher Full Text

7. Lodise TP, Drusano GL, Zasowski E, et al.: Vancomycin exposure in patients with methicillin-resistant Staphylococcus aureus bloodstream infections: How much is enough? Clin Infect Dis. 2014; 59(5): 666-75. PubMed Abstract | Publisher Full Text

8. Lodise TP, Rosenkranz SL, Finnemeyer M, et al.: The Emperor's New Clothes: PRospective Observational Evaluation of the Association Between Initial Vancomycln Exposure and Failure Rates Among ADult HospitalizEd Patients With Methicillin-resistant Staphylococcus aureus Bloodstream Infections (PROVIDE). Clin Infect Dis. 2020; 70(8): 1536-45. PubMed Abstract | Publisher Full Text | Free Full Text Faculty Opinions Recommendation

9. Rybak MJ, Le J, Lodise TP, et al.: Therapeutic monitoring of vancomycin for serious methicillin-resistant Staphylococcus aureus infections: A revised consensus guideline and review by the American Society of Health-System Pharmacists, the Infectious Diseases Society of America, the Pediatric Infectious Diseases Society, and the Society of Infectious Diseases Pharmacists. Am J Health Syst Pharm. 2020; 77(11): 835-64. PubMed Abstract | Publisher Full Text | Faculty Opinions Recommendation

10. Neely MN, Youn G, Jones B, et al:: Are vancomycin trough concentrations adequate for optimal dosing? Antimicrob Agents Chemother. 2014; 58(1): 309-16.

PubMed Abstract | Publisher Full Text | Free Full Text

11. Neely MN, Kato L, Youn G, et al:: Prospective Trial on the Use of Trough Concentration versus Area under the Curve To Determine Therapeutic Vancomycin Dosing. Antimicrob Agents Chemother. 2018; 62(2): e02042-17. PubMed Abstract | Publisher Full Text | Free Full Text

12. Meng L, Wong T, Huang S, et al:: Conversion from Vancomycin Trough Concentration-Guided Dosing to Area Under the Curve-Guided Dosing Using Two Sample Measurements in Adults: Implementation at an Academic Medical Center. Pharmacotherapy. 2019; 39(4): 433-42. PubMed Abstract | Publisher Full Text

13. Heil EL, Claeys KC, Mynatt RP, et al:: Making the change to area under the curve-based vancomycin dosing. Am J Health Syst Pharm. 2018; 75(24): 1986-95.

PubMed Abstract | Publisher Full Text

14. Finch NA, Zasowski EJ, Murray KP, et al:: A Quasi-Experiment To Study the Impact of Vancomycin Area under the Concentration-Time Curve-Guided Dosing on Vancomycin-Associated Nephrotoxicity. Antimicrob Agents Chemother. 2017; 61(12): e01293-17. PubMed Abstract | Publisher Full Text | Free Full Text

15. Gregory ER, Burgess DR, Cotner SE, et al:: Vancomycin Area Under the Curve Dosing and Monitoring at an Academic Medical Center: Transition Strategies and Lessons Learned. J Pharm Pract. 2020; 33(6): 774-8. PubMed Abstract | Publisher Full Text | Faculty Opinions Recommendation

16. Diaz R, Afreixo V, Ramalheira E, et al.: Evaluation of vancomycin MIC creep in methicillin-resistant Staphylococcus aureus infections-a systematic review and meta-analysis. Clin Microbiol Infect. 2018; 24(2): 97-104. PubMed Abstract | Publisher Full Text

17. Sader HS, Farrell DJ, Flamm RK, et al.: Activity of ceftaroline and comparator agents tested against Staphylococcus aureus from patients with bloodstream infections in US medical centres (2009-13). J Antimicrob Chemother. 2015; 70(7): 2053-6.

PubMed Abstract | Publisher Full Text

18. Diaz R, Ramalheira E, Afreixo V, et al:: Evaluation of vancomycin MIC creep in Staphylococcus aureus. J Glob Antimicrob Resist. 2017; 10: 281-4. PubMed Abstract | Publisher Full Text

19. Rybak MJ, Vidaillac C, Sader HS, et al.: Evaluation of vancomycin susceptibility 
testing for methicillin-resistant Staphylococcus aureus: Comparison of Etest and three automated testing methods. J Clin Microbiol. 2013; 51(7): 2077-81. PubMed Abstract | Publisher Full Text | Free Full Text

20. Davis JS, van Hal S, Tong SYC: Combination antibiotic treatment of serious methicillin-resistant Staphylococcus aureus infections. Semin Respir Crit Care Med. 2015; 36(1): 3-16.

PubMed Abstract | Publisher Full Text

21. Barber KE, Werth BJ, Rybak MJ: The combination of ceftaroline plus daptomycin allows for therapeutic de-escalation and daptomycin sparing against MRSA. J Antimicrob Chemother. 2015; 70(2): 505-9.

PubMed Abstract | Publisher Full Text | Free Full Text

22. Sakoulas G, Okumura CY, Thienphrapa W, et al:: Nafcillin enhances innate immune-mediated killing of methicillin-resistant Staphylococcus aureus. J Mol Med (Berl). 2014; 92(2): 139-49.

PubMed Abstract | Publisher Full Text | Free Full Text

23. Ho SW, Jung D, Calhoun JR, et al.: Effect of divalent cations on the structure of the antibiotic daptomycin. Eur Biophys J. 2008; 37(4): 421-33. PubMed Abstract | Publisher Full Text

24. Henson KER, Yim J, Smith JR, et al.: $\beta$-Lactamase Inhibitors Enhance the Synergy between $\beta$-Lactam Antibiotics and Daptomycin against MethicillinResistant Staphylococcus aureus. Antimicrob Agents Chemother. 2016; 61(1): e01564-16.

PubMed Abstract | Publisher Full Text | Free Full Text

25. Deresinski S: Vancomycin in combination with other antibiotics for the treatment of serious methicillin-resistant Staphylococcus aureus infections. Clin Infect Dis. 2009; 49(7): 1072-9.

PubMed Abstract | Publisher Full Text

26. Davis JS, Sud A, O'Sullivan MVN, et al: Combination of Vancomycin and $\beta$ Lactam Therapy for Methicillin-Resistant Staphylococcus aureus Bacteremia: A Pilot Multicenter Randomized Controlled Trial. Clin Infect Dis. 2016; 62(2): 173-80.

PubMed Abstract | Publisher Full Text

27. Tong SYC, Lye DC, Yahav D, et al.: Effect of Vancomycin or Daptomycin With vs Without an Antistaphylococcal $\beta$-Lactam on Mortality, Bacteremia, Relapse, or Treatment Failure in Patients With MRSA Bacteremia: A Randomized Clinical Trial. JAMA. 2020; 323(6): 527-37. PubMed Abstract | Publisher Full Text | Free Full Text Faculty Opinions Recommendation

28. Sakoulas G, Moise PA, Casapao AM, et al:: Antimicrobial salvage therapy for persistent staphylococcal bacteremia using daptomycin plus ceftaroline. Clin Ther. 2014; 36(10): 1317-33. PubMed Abstract | Publisher Full Text

29. Geriak M, Haddad F, Rizvi K, et al.: Clinical Data on Daptomycin plus Ceftaroline versus Standard of Care Monotherapy in the Treatment of Methicillin-Resistant Staphylococcus aureus Bacteremia. Antimicrob Agents Chemother. 2019; 63(5): e02483-18.

PubMed Abstract | Publisher Full Text | Free Full Text

Faculty Opinions Recommendation

30. Zasowski EJ, Trinh TD, Atwan SM, et al:: The Impact of Concomitant Empiric Cefepime on Patient Outcomes of Methicillin-Resistant Staphylococcus aureus Bloodstream Infections Treated With Vancomycin. Open Forum Infect Dis. 2019; 6(7): ofz077.

PubMed Abstract | Publisher Full Text | Free Full Text

31. Truong J, Veillette JJ, Forland SC: Outcomes of Vancomycin plus a $\beta$-Lactam versus Vancomycin Only for Treatment of Methicillin-Resistant Staphylococcus aureus Bacteremia. Antimicrob Agents Chemother. 2018; 62(2): e01554-17. PubMed Abstract | Publisher Full Text | Free Full Text

32. Jorgensen SCJ, Zasowski EJ, Trinh TD, et al.: Daptomycin Plus $\beta$-Lactam Combination Therapy for Methicillin-resistant Staphylococcus aureus Bloodstream Infections: A Retrospective, Comparative Cohort Study. Clin Infect Dis. 2020; 71(1): 1-10.

PubMed Abstract | Publisher Full Text | Faculty Opinions Recommendation

33. McCreary EK, Kullar R, Geriak M, et al: Multicenter Cohort of Patients With Methicillin-Resistant Staphylococcus aureus Bacteremia Receiving Daptomycin Plus Ceftaroline Compared With Other MRSA Treatments. Open Forum Infect Dis. 2019; 7(1): ofz538.

PubMed Abstract | Publisher Full Text | Free Full Text |

Faculty Opinions Recommendation

34. Watkins RR, Deresinski S: Increasing Evidence of the Nephrotoxicity of Piperacillin/Tazobactam and Vancomycin Combination Therapy-What Is the Clinician to Do? Clin Infect Dis. 2017; 65(12): 2137-43. PubMed Abstract | Publisher Full Text

35. Avedissian SN, Pais GM, Liu J, et al.: Piperacillin-Tazobactam Added to Vancomycin Increases Risk for Acute Kidney Injury: Fact or Fiction? Clin Infect Dis. 2020; 71(2): 426-32.

PubMed Abstract | Publisher Full Text | Faculty Opinions Recommendation

36. Liu C, Bayer A, Cosgrove SE, et al:: Clinical practice guidelines by the infectious diseases society of america for the treatment of methicillin-resistant Staphylococcus aureus infections in adults and children: Executive summary.
Clin Infect Dis. 2011; 52(3): 285-92. PubMed Abstract | Publisher Full Text

37. Gasch O, Camoez M, Domínguez MA, et al.: Emergence of resistance to daptomycin in a cohort of patients with methicillin-resistant Staphylococcus aureus persistent bacteraemia treated with daptomycin. $J$ Antimicrob Chemother. 2014; 69(2): 568-71.

PubMed Abstract | Publisher Full Text

38. Kalil AC, Holubar M, Deresinski S, et al.: Is Daptomycin plus Ceftaroline Associated with Better Clinical Outcomes than Standard of Care Monotherapy for Staphylococcus aureus Bacteremia? Antimicrob Agents Chemother. 2019; 63(11): e00900-19.

PubMed Abstract | Publisher Full Text | Free Full Text

39. Lexicomp Online, Pediatric and Neonatal Lexi-Drugs Online. Micromedex® Healthcare Series [Internet database]. 2015.

40. Cosimi RA, Beik N, Kubiak DW, et al: Ceftaroline for Severe MethicillinResistant Staphylococcus aureus Infections: A Systematic Review. Open Forum Infect Dis. 2017; 4(2): ofx084. PubMed Abstract | Publisher Full Text | Free Full Text

41. Burnett YJ, Echevarria K, Traugott KA: Ceftaroline as Salvage Monotherapy for Persistent MRSA Bacteremia. Ann Pharmacother. 2016; 50(12): 1051-1059. PubMed Abstract | Publisher Full Text

42. Vidaillac $\mathrm{C}$, Leonard $\mathrm{SN}$, Rybak MJ: In vitro activity of ceftaroline against methicillin-resistant Staphylococcus aureus and heterogeneous vancomycinintermediate $\mathrm{S}$. aureus in a hollow fiber model. Antimicrob Agents Chemother. 2009; 53(11): 4712-7. PubMed Abstract | Publisher Full Text | Free Full Text

43. Ahmad O, Crawford TN, Myint T: Comparing the Outcomes of Ceftaroline Plus Vancomycin or Daptomycin Combination Therapy Versus Monotherapy in Adults with Complicated and Prolonged Methicillin-Resistant Staphylococcus Aureus Bacteremia Initially Treated with Supplemental Ceftaroline. Infect Dis Ther. 2020; 9(1): 77-87.

PubMed Abstract | Publisher Full Text | Free Full Text | Faculty Opinions Recommendation

44. Cheng MP, Lawandi A, Butler-Laporte G, et al:: Adjunctive Daptomycin in the Treatment of Methicillin-susceptible Staphylococcus aureus Bacteremia: A Randomized, Controlled Trial. Clin Infect Dis. 2021; 72(9): e196-e203. PubMed Abstract | Publisher Full Text | Faculty Opinions Recommendation

45. Holland TL, Chambers HF, Boucher HW, et al:: Considerations for Clinical Trials of Staphylococcus aureus Bloodstream Infection in Adults. Clin Infect Dis. 2019; 68(5): 865-72. PubMed Abstract | Publisher Full Text | Free Full Text | Faculty Opinions Recommendation

46. Kale-Pradhan PB, Giuliano C, Jongekrijg A, et al:: Combination of Vancomycin or Daptomycin and Beta-lactam Antibiotics: A Meta-analysis. Pharmacotherapy. 2020; 40(7): 648-58. PubMed Abstract | Publisher Full Text | Faculty Opinions Recommendation

47. del Río A, García-de-la-Mària C, Entenza JM, et al.: Fosfomycin plus $\beta$-Lactams as Synergistic Bactericidal Combinations for Experimental Endocarditis Due to Methicillin-Resistant and Glycopeptide-Intermediate Staphylococcus aureus. Antimicrob Agents Chemother. 2015; 60(1): 478-86. PubMed Abstract | Publisher Full Text | Free Full Text

48. García-de-la-Mària C, Gasch O, García-Gonzalez J, et al:: The Combination of Daptomycin and Fosfomycin Has Synergistic, Potent, and Rapid Bactericidal Activity against Methicillin-Resistant Staphylococcus aureus in a Rabbit Model of Experimental Endocarditis. Antimicrob Agents Chemother. 2018; 62(6): e02633-17.

PubMed Abstract | Publisher Full Text | Free Full Text

49. Falagas ME, Vouloumanou EK, Samonis G, et al.: Fosfomycin. Clin Microbio Rev. 2016; 29(2): 321-47.

PubMed Abstract | Publisher Full Text | Free Full Text | Faculty Opinions Recommendation

50. Pujol M, Miró JM, Shaw E, et al:: Daptomycin Plus Fosfomycin Versus Daptomycin Alone for Methicillin-resistant Staphylococcus aureus Bacteremia and Endocarditis: A Randomized Clinical Trial. Clin Infect Dis. 2021; 72(9): $1517-1525$

PubMed Abstract | Publisher Full Text | Free Full Text | Faculty Opinions Recommendation

51. Nabriva Therapeutics Receives FDA Acknowledgement of New Drug Application Resubmission for Intravenous CONTEPO'T (fosfomycin) for InjectionPDUFA action date set for June 19, 2020. 2020; [cited 2020 10/13/20]. Reference Source

52. Dotel R, Tong SYC, Bowen A, et al:: CASSETTE-clindamycin adjunctive therapy for severe Staphylococcus aureus treatment evaluation: Study protocol for a randomised controlled trial. Trials. 2019; 20(1): 353. PubMed Abstract | Publisher Full Text | Free Full Text

53. Fowler VG Jr, Olsen MK, Ralph Corey G, et al.: Clinical identifiers of complicated Staphylococcus aureus bacteremia. Arch Intern Med. 2003; 163(17): 2066-72. PubMed Abstract | Publisher Full Text 
54. Chong YP, Park SJ, Kim HS, et al:: Persistent Staphylococcus aureus bacteremia: A prospective analysis of risk factors, outcomes, and microbiologic and genotypic characteristics of isolates. Medicine (Baltimore). 2013; 92(2): 98-108.

PubMed Abstract | Publisher Full Text | Free Full Text

55. Khatib R, Johnson LB, Fakih MG, et al:: Persistence in Staphylococcus aureus bacteremia: Incidence, characteristics of patients and outcome. Scand $J$ Infect Dis. 2006; 38(1): 7-14.

PubMed Abstract | Publisher Full Text | Faculty Opinions Recommendation

56. Gasch O, Camoez M, Dominguez MA, et al.: Lack of association between genotypes and haematogenous seeding infections in a large cohort of patients with methicillin-resistant Staphylococcus aureus bacteraemia from 21 Spanish hospitals. Clin Microbiol Infect. 2014; 20(4): 361-7.

PubMed Abstract | Publisher Full Text

57. Goldberg E, Paul M, Talker O, et al.: Co-trimoxazole versus vancomycin for the treatment of methicillin-resistant Staphylococcus aureus bacteraemia: A retrospective cohort study. J Antimicrob Chemother. 2010; 65(8): 1779-83. PubMed Abstract | Publisher Full Text

58. Lewis PO, Heil EL, Covert KL, et al:: Treatment strategies for persistent methicillin-resistant Staphylococcus aureus bacteraemia. J Clin Pharm Ther. 2018; 43(5): 614-25

PubMed Abstract | Publisher Full Text

59. Kuehl R, Morata L, Boeing C, et al.: Defining persistent Staphylococcus aureus bacteraemia: Secondary analysis of a prospective cohort study. Lancet Infect Dis. 2020; 20(12): 1409-17.

PubMed Abstract | Publisher Full Text | Faculty Opinions Recommendation

60. Minejima E, Mai N, Bui N, et al:: Defining the Breakpoint Duration of Staphylococcus aureus Bacteremia Predictive of Poor Outcomes. Clin Infect Dis. 2020; 70(4): 566-73.

PubMed Abstract | Publisher Full Text | Free Full Text |

Faculty Opinions Recommendation

61. Doernberg SB, Tran TTT, Tong SYC, et al:: Good Studies Evaluate the Disease While Great Studies Evaluate the Patient: Development and Application of a Desirability of Outcome Ranking Endpoint for Staphylococcus aureus Bloodstream Infection. Clin Infect Dis. 2019; 68(10): 1691-1698. PubMed Abstract | Publisher Full Text | Free Full Text |

Faculty Opinions Recommendation 